\title{
Left Dislocation: a typological overview
}

\author{
Josh Westbury \\ Department of Ancient Languages, Stellenbosch University, South Africa | Faithlife Corporation (Logos Bible \\ Software), USA \\ E-mail: joshwestbury@gmail.com
}

\begin{abstract}
The Left Dislocation construction is a typologically universal phenomenon that has received detailed analysis, from both formal and functional perspectives, in a number of genetically and areally diverse languages. The present paper aims to provide a general overview of this crosslinguistic research with a concentration on: 1) the comparison of syntactico-semantic features of LD across languages, 2) the generalized cross-linguistic patterns and categories attested for LD, and 3) the explanations offered for LD in terms of its motivation and function in discourse. Accordingly, the paper will proceed in two parts. The first part will entail a brief survey of the syntactic and semantic attributes that have established LD as a typological category. In light of these attributes, linguists generally distinguish between two broad types of LD on the basis of particular syntactic patterns and constraints. Thus, a general description of these types is provided, along with a brief description of several less prototypical LD types. The second part of the paper will focus on the explanation of LD both in terms of the cognitive and contextual constraints that motivate its use in discourse, as well as the communicative goals and pragmatic effects achieved by the construction in particular contexts.
\end{abstract}

Keywords: Typology, Left Dislocation, Syntax, Discourse Pragmatics, Information Structure

\section{Introduction}

The grammatical construction known as Left Dislocation (=LD) is represented by the English sentence in (1a). In this example, the proper noun Peter occurs in a dislocated position before the clause, and is resumed within the clause by a co-referential pronoun him, the direct object of the verb known. This LD construction is juxtaposed with its canonical counterpart in (1b) in which Peter occurs in situ as the direct object of the verb:

(1) a. [Peter, $]_{\mathrm{i}}$ I've known him for $_{\mathrm{i}}$ a long time.

b. I’ve known Peter for a long time. 
There is a growing body of literature on the LD construction, with detailed descriptions available for a number of genetically and areally diverse languages. ${ }^{1}$ These studies reflect an array of approaches, theoretical frameworks, and areas of concentration (e.g. syntax, pragmatics, etc.), and showcase the range of possible structures and functions exhibited by LD constructions across languages.

In light of this research, it is reasonable to hypothesize that LD is a universal linguistic phenomenon, as it occurs in most, if not all, documented language of the world (Lambrecht 2001: 1051, Lopez forthcoming). ${ }^{2}$ This hypothesis stands in accordance with the constraint proposed by Moravcsik (2011: 69) that "[a] universal hypothesis is reasonable if it is based on a large, genetically and areally balanced sample; or if it is predicted by an independently motivated principle; or if both are the case.” Research increasingly suggests that the LD construction satisfies both of these conditions. That is to say that, in addition to its ubiquity across languages which vary in geographic or genetic affiliation, the use of LD is predicted by cognitively motivated principles and discourse-pragmatic constraints. ${ }^{3}$

This paper aims to provide a general overview of cross-linguistic research on LD, with a particular focus on: ${ }^{4}$

1. The comparison of syntactico-semantic features of LD across languages,

2. The generalization of cross-linguistic patterns, as well as the categories that have emerged from these patterns.

3. Explanations of generalized patterns in terms of their motivation and function in discourse.

This overview will proceed in two parts. The first part entails a brief description of the syntactic and semantic attributes that have established LD as a typological category. In light of these attributes, linguists generally distinguish between two broad types of LD on the basis of particular syntactic patterns and constraints. A general description of these types is provided, along with a brief description of several less prototypical LD types. The second part will aim to provide an explanation of LD both in terms of the cognitive and contextual constraints that motivate its use in discourse, as well as the communicative goals and pragmatic effects achieved by the construction in particular contexts.

\footnotetext{
1 A short list of notable studies includes: Romance (Barnes 1985, Cinque 1977 1983/1997 1990, De Cat 2007 a,b; Delais-Roussaire et al. 2004, Frascarelli 2000, Dobrovie-Sorin 1994, Lambrecht 1981 1994, Rizzi 1997, SamekLodovici 2005 2006, Villalba 2000, 2009), Greek (Anagnostopoulou 1994 1997), Semitic (Gross 1987, Khan, 1988, Aoun and Benmamoun 1998, Westbury 2014, Holmstedt 2015, Korchin 2015), Albanian (Kallulli 1999), Sumerian (Zólyomi 2005), Germanic (Frey 2005, Grohmann, 2003, Boeckx and Grohmann 2005, Ott forthcoming, Geluykens 1992, 1993, Van Riemsdjik and Zwarts 1997, Vat 1981/1997, Zaenen 1997, Tizón-Couto 2012), Bantu (Bresnan and Mchombo 1987, Baker 2003), Mohawk (Baker 1996), Slavic (Sturgeon 2006; Arnaudova 2004), Persian (Moezzipour 2013). Cf. also Anagnostopoulou et al. (1997).

2 According to Moravcsik (2011: 69), a linguistic universal is any "grammatical characteristic that can be reasonably hypothesized to be present in all or most human languages.”

3 The focus of this paper is on LD constructions in so-called "non-polysynthetic" languages, since it is only with these languages that dislocation is non-obligatory, and therefore reflect distinct discourse pragmatic functions (cf. Baker 1996; Lopez forthcoming).

4 Note that these three aims correspond to Croft's three-pronged definition of empirical typological analysis, namely: comparison, generalization, and explanation (Croft 2003: 1-2).
} 


\section{Syntactico-Semantic Features: Generalization and Classification}

A comparison of LD constructions across languages exposes an array of syntactic and semantic features. Some features are characteristic of specific languages or are isolated to particular language families, while others reflect more generalized and universally attested patterns. Despite this diversity, there is a general consensus that the prototypical LD schema is comprised of the following prototypical attributes: ${ }^{5}$

1. A referential constituent both precedes and is dislocated from a core clause with which it is associated.

2. An alternative position for the dislocated constituent exits within the associated core clause.

3. The alternative position is filled by an anaphoric co-referential resumptive element in the form of a regular or clitic pronominal, or an epithet.

4. The dislocated constituent is accompanied by a separate intonation contour.

The presence or absence of an intra-clausal co-referential element has traditionally functioned as a syntactic litmus test for the identification of LD constructions across languages. This distinctive feature was first described by Ross in his widely influential doctoral dissertation entitled Constraints on Variables in Syntax (1967). According to Ross, the co-referential resumptive differentiates the LD construction from the structurally similar Topicalization construction. ${ }^{6}$ In the later, a constituent is placed in the leftmost position leaving behind a gap in its canonical position, as shown in (2b), while in the former, an anaphoric pronominal copy occurs in the canonical position, as in (2c). ${ }^{7}$

\footnotetext{
5 These attributes have been adapted from Lambrecht (2001: 1050).

6 The term "topicalization" is misleading as it implies that the initial constituent always fulfills a topic function. However, cross-linguistic research has shown that these constructions often fulfill a focus function as well. Thus, the term "topicalization" has increasingly fallen out of vogue in more recent years in favor of the more neutral and structurally descriptive term "fronting".

7 Ross argued that LD constructions are derived through a specific copying rule. This rule stipulates that a constituent is moved to the leftmost position in the sentence while leaving a pronominal copy in the source position, one that anaphorically refers back to the leftmost NP. The dislocated constituent and the pronominal copy are understood as co-referential as a result of the movement transformation. For Ross, the copying rule was the differentiating factor between LD constructions and so-called 'Topicalization Constructions'. By contrast, Topicalization constructions were the result of a "chopping rule" in which a constituent undergoes movement to a fronted position but leaves behind no trace of itself whatsoever in the source position. Moreover, chopping rules were subject to Ross' constraints on variables - the Complex Noun Phrase Constraint (CNPC), the Sentential Subject Constraint (CSC) and the Coordinate Structure Constraint (CSC)—while copying rules were not.

Despite their significance within early versions of generative grammar, Ross's transformational analyses of LD constructions were, for the most part, abandoned in later versions of the theory in favor of a view that construes the structural properties of LD constructions as base generated. In other words, the dislocated constituent is largely assumed to be in a non-argument position through adjunction to the sentence which, along with the coreferential resumptive pronoun, is assumed to be inserted directly from the lexicon into the syntactic structure of the sentence rather than having been derived through movement operations (van Riemsdijk 1997: 3). For cogent arguments against Ross's transformational description of LD, see van Riemsdijk and Zwarts (1974/1997), Rodman (1974/1997) Hirschbühler (1975), Gundel (1975), Chomsky (1977), Rivero (1980), Radford (1988), Haegeman (1991), van der Spuy (1993), Rodman (1997), van Riemsdijk (1997); and pertaining to Biblical Hebrew in particular, see Naudé (1990). Moreover, for a base-generated description of English LD, see Rodman (1974), Hirschbüler (1975), van Riemskijk and Zwarts (1974), Chomsky (1977), Vat (1981), Cinque (1983), BarcelonaSanchez (1988), Lasnik and Saito (1992), and Lyons (1999).
} 
(2)
a. I saw this movie when I was a kid
(Canonical)
b. This movie I saw when I was a kid
(Topicalization / Fronting)
c. [This movie $]_{i}$, I saw it $t_{i}$ when I was a kid
(LD)

Unlike both the canonical and fronting constructions in (2a) and (2b), the coreferential resumptive pronoun it in (2c) satisfies the valency requirement of the verb saw, thus orphaning, or dislocating the leftmost NP This movie outside of the semantic and syntactic dependency relations licensed by the predicate. In other words, the critical difference between these constructions, is that the dislocated NP This movie can be omitted in (2c) without causing any structural violations, while this cannot be said of the NP in either the fronting or canonical constructions.

\section{$2.1 \quad$ H-Type and C-Type LD}

More than an identifying feature, the co-referential resumptive has traditionally served as the primary means by which linguists distinguish between different structural types of LD across languages. In particular, general patterns and constraints, such as the form of the resumptive, morphological agreement, and constraints on locality, ${ }^{8}$ have motivated researchers, particularly within the generative tradition, to distinguish two heuristic structural categories, commonly referred to as: 1) Hanging Topic LD (H-Type), and 2) Clitic LD (C-Type). ${ }^{9}$ The Spanish LD constructions in (3) are representative of both of these types:

Spanish (Alexiadou 2006: 670)
a.
[Berdardo]i
estoy segura que nadie
confia
Bernardo
en ese idiota $_{i}$
(I) am sure that nobody has confidence
(H-Type)
in that idiot
"(As for) Bernardo, I am sure that nobody has confidence in that idiot"
b. [A sus amigos] $]_{i}$, Pedro los invite
ACC his friends Pedro CL-ACC invited-3sg
a cenar
to dine
"As for his friends, Pedro invited them to dine"

First and foremost, H-Type and C-Type LDs are distinguished by the prototypical form of the co-referential resumptive in each type. The resumptive in H-Type constructions can be a strong or weak pronoun (e.g. a clitic), an agreement morpheme, or even an epithet, such as the phrase

\footnotetext{
${ }^{8}$ Cf. Van Riemsdijk (1997); Alexiadou (2006); and Lopez (2009, forthcoming) for further details.

${ }^{9}$ These terms can be traced back to Cinque $(1983,1990)$. Strictly speaking, there are actually three general types of LD recognized by researches working within the Generative tradition. Originally, HTLD was associated with English, CLLD with Italian, and a third type, "Contrastive Left Dislocation" (CLD), with Dutch. Much of the variation that was discovered was thought to be related in some form or another to the resumptive element-i.e. whether the resumptive is a regular pronoun (HTLD), a special pronoun (e.g. a demonstrative) (CLD), or a clitic (CLLD) (van Riemsdijk 1997: 4). CLD, is a "typical Germanic construction which is characterized by the fact that the resumptive element inside the matrix clause is a demonstrative pronoun, which must be adjacent to the LD-ed element" (Alexiadou 2006: 687). Since CLD is a much more language specific phenomenon, we will not consider it further here.
} 
ese idiota in (3a). The the resumptive in C-Type constructions, on the other hand, is obligatorily a clitic pronoun, as in los in (3b), or an agreement morpheme (cf. Lopez forthcoming: 4). ${ }^{10}$ Furthermore, the form of the resumptive is indicative of the sort of connection the dislocated constituent holds with the core clause in each type. In particular, strong pronouns, and epithets characteristic of H-type constructions, imply a weaker connection between the dislocated constituent and the core clause, while the clitic resumptive in C-Type constructions evinces stronger connectivity in this respect (Lopez forthcoming: 2). This highlights the fact that the grammatical category of resumption is scalar notions. In other words, a given LD construction can be said to exhibit resumption to a greater or lesser degree. Moreover, this also implies that the same holds for the dislocated status of the initial constituent, which may be more or less detached from the following matrix clause. In other words, the connectedness of the dislocate to its matrix clause is a matter of degree.

In addition to the form of the resumptive, researchers have observed other syntactic and morphological connectivity patterns distinctive of C-Type and H-Type constructions, respectively. For instance, H-Type constructions typically show no sensitivity to locality constraints, (e.g. island effects), or so-called reconstruction effects, such as quantifier variable relations or binding theory violations (e.g. Condition-C violation) (Lopez forthcoming: 2; Alexiadou 2006: 678-681). However, this is generally not true of C-Type constructions in which the relation between the dislocated constituent and the resumptive clitic is typically subject to both island and reconstruction effects. The juxtaposition of the two Greek constructions in (4) demonstrates the asymmetry between H-Type and C-Type LD constructions with respect to locality constraints.

Greek (Alexiadou 2006: 673)
a.
$\left[\right.$ I Maria $_{i} \quad$ htes
gnorisa

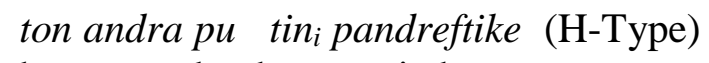 the Mary-NOM yesterday met the man that her married
"As for Mary, I met yesterday the man that married her"
b. $\quad *[\text { Tin Maria }]_{i}$ htes gnorisa ton andra pu tin $n_{i}$ pandreftike (C-Type) the Mary-ACC yesterday met the man that her married

The ungrammaticality of (4b) is due to the embedded resumptive clitic which violates the constraint on locality imposed by the relative clause island. By contrast, the embedded resumptive in the corresponding H-Type construction in (4a) causes no such violation. ${ }^{11}$ This sensitivity to island effects suggests that C-Type constructions are more connected to the core clause than their H-Type counterparts.

\footnotetext{
10 This constraint derives from research in Romance languages and Greek. In other languages, such as Lebanese Arabic, there is evidence that resumptives in C-type constructions can be epithets as well (Aoun and Choueiri 2000). Moreover, Lopez draws a connection between C-type LDs and fronting (his “topicalization”) in languages that do not have clitics, such as English. He suggests that a fine line cannot be drawn between two the constructions since fronting behaves similarly to C-type LD, particularly with respect to island and reconstruction effects. For further discussion, see (Lopez forthcoming: 5).

${ }^{11}$ It is worth noting that C-Type constructions are generally only sensitive to strong islands, not weak islands (Alexiadou 2006: 682). However, in some languages, such as Lebanese Arabic, it is possible for C-Type constructions to violate syntactic islands (Alexiadou 682).
} 
Furthermore, C-Type and H-Type LDs are also distinguished by the morphological connectedness of the resumptive and dislocated constituent. Although the resumptives in both C-Type and H-Type constructions agree with the dislocated constituent in person, number and gender, C-Type constructions also exhibit case agreement in languages that inflect for case. This asymmetry is seen in the Spanish H-Type and C-Type constructions in (5), repeated from (3) above: ${ }^{12}$

(5) Spanish (Alexiadou, 2006:670)
a. [A sus amigos $]_{i}$, Pedro los ${ }_{i} \quad$ invitó ACC his friends Pedro CL-ACC invited-3sg

In contrast to the H-Type construction in (5b), the dislocated constituent in (5a) is introduced by the differential object marker $A$, marking agreement with the accusative resumptive clitic los within the clause. ${ }^{13}$

In addition to differences in connectivity effects, H-Type and C-Type constructions are also distinguished on the basis of more general syntactic patterns and distributional constraints. In particular, H-Type constructions generally exhibit tighter constraints with respect to: 1) the form of the dislocated constituent, 2) the amount of constituents permitted in the left-dislocated position, and 3) whether the construction can occur in embedded contexts. For instance, the form of the dislocated constituent in H-Type constructions is typically constrained to either referential definite or specific indefinite NPs, while the dislocated constituent in C-Type constructions can be of any maximal phase type, such as PPs, APs, AdvPs, or VPs (cf. Alexiadiou 2006: 671, Lambrecht 2001: 1061-1065). Likewise, H-Type constructions generally permit only one dislocated constituent. By contrast, no such constraint holds for CType constructions, in which multiple constituents may occur in the left-dislocated position.

In addition to resumption, and other connectivity effects, the two constructions types also differ with respect to constraints on syntactic distribution. H-Type constructions are generally restricted to so-called "root" or non-embedded clause types (e.g. independent clauses), while C-Type constructions are perfectly acceptable in both embedded and non-embedded contexts.

\footnotetext{
12 See also a similar situation in Polish (Andrason 2016).

${ }^{13}$ Some researchers have also suggested that, in addition to syntactic and morphological properties, the size of the intonation break between the dislocated constituent and the core clause further suggests that dislocated constituents in H-Type constructions exhibit a weaker connection to the core clause than their C-Type counterparts. While sharp intonation breaks are characteristic of H-Type constructions, the intonation break in C-Type constructions is generally much weaker (cf. Anagnostopoulou 1997, Alexiadou 2006, Olarrea 2012). However, see Feldhausen (2012) for an opposing view.
} 
Lastly, it is worth noting that the differences between H-type and C-type-with respect to their differing connectivity effects and syntactic/distribution constraints-can be interpreted as evidence that C-type constructions occupy a higher stage on the grammaticalization cline than H-type constructions (see Andrason, Westbury \& van der Merwe 2016). That is to say that, as the LD construction becomes more grammaticalized, thus moving closer to the prototypical fronting construction, we expect it to exhibit more connectivity (i.e. between the dislocate and the matrix clause) and become distributed in wider contexts of use (e.g. as occurs with fronting); and indeed, as discussed above, this is generally what is observed with C-type constructions.

\section{$2.2 \quad$ Non-Resumptive LD}

Thus far, the discussion has focused on several asymmetric connectivity effects, in addition to various syntactic and distributional constraints that have motivated researchers, particularly within the generative tradition, to draw a typological distinction between H-Type and C-Type constructions. Moreover, notwithstanding their formal differences, it is generally assumed that both H-Type and C-Type constructions depend on a coreferential resumptive of some type, either overtly or implicitly expressed, to satisfy the minimal syntactico-semantic requirements for LD. $^{14}$ In other words, following Ross, it has almost gone without saying that LD constructions in general are classified as such based on the presence of a coreferential resumptive within the core clause. (Note that here, the term "resumptive" is reserved only for those referents that are in a total identity relation-i.e. coreferential-with the referent of another constituent.)

However, other constructions are observed in which there exists no coreferential resumptive (i.e. total identity relation), while the leftmost constituent nevertheless appears to be, in some sense, dislocated from the core clause. Consider the following constructions in (6)-(8) taken from English, French, Sumerian and Indonesian: ${ }^{15}$

Metonymic Relation

Indonesian (Li and Thompson 1976: 470)

$\begin{array}{lll}\text { a. } \quad[\text { Anak itu }]_{i}, \text { ibu-nja } & \text { membeli } & \text { sepatu } \\ \text { child that mother-POSS buy } & \text { shoes } \\ \text { "That child, his mother bought shoes" } & \end{array}$

Sumerian (Zólyomi 2005: 169)

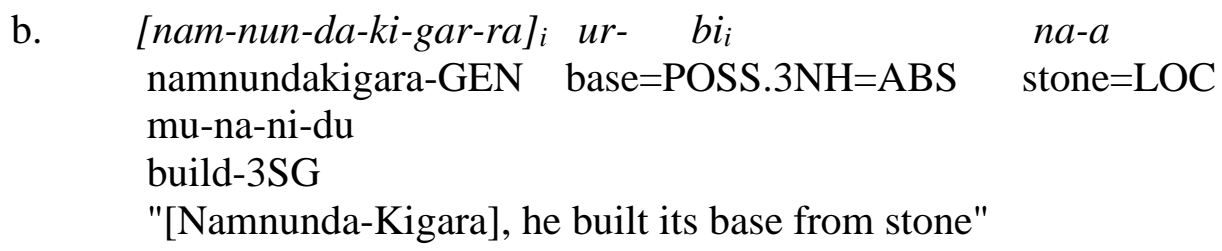

\footnotetext{
14 Note, however, that from a cognitive linguistic/typological standpoint, LD constructions with implicit resumption are less prototypical than those exhibiting overt resumption.

15 For similar constructions in Neo-Aramaic, see Khan (2016).
} 
a. [Mon premier mari], on avait une voiture puis une moto "My first husband, we had a car then a motorcycle"

English (Lambrecht 2001: 1058)

b. That isn't the typical family anymore, [The typical family today], the husband and the wife both work

\section{Relevance Relation}

a. $\quad$ [As for education], John prefers Bertrand Russell's ideas (Lambrecht 2001: 1058)

b. [The Beatles], without Sgt. Pepper, we wouldn't even have half of the pop music we have now

Constructions of this type are commonly referred to as "Chinese-Style Topic Constructions" (cf. Chafe 1976, Li and Thompson 1976, Lambrecht 2001, inter alia). Despite the lack of a coreferential resumptive, the referent of the dislocated constituent is related, either semantically or pragmatically to the associated proposition, thus providing further evidence that the notion of resumption is indeed a scalar notion (see above). In particular, the dislocated referent may be semantically linked to another referent within the clause, in which case the relationship is characterized as either metonymic (6), ${ }^{16}$ or partial (7). Alternatively, the referent may stand in a pragmatic relevance relation to the proposition as a whole (cf. Tizón-Couto 2012: 38-39; Lambrecht 2001: 1058).

A metonymic relation, illustrated by the two constructions in (6), is one in which the referent of the dislocated constituent stands in either a hypernemic relation (e.g. whole/part) or hyponymic relation (e.g. part/whole) with another referent expressed within the core clause. Often the clause internal element with which the dislocated constituent is metonymically linked takes the form of a full NP modified by a possessive determiner.

A partial identity relation, as the name suggests, entails a partial overlap in referents denoted by the dislocated constituent and another clause internal element, respectively. The constructions in (7) are representative of a partial identity relation.

Finally, there are constructions like those in (8) in which a direct semantic link, either metonymic, partial, or otherwise, does not hold between the dislocated constituent and the core clause. The referent of the dislocated constituent in these constructions rather stands in a relevance relation to the ensuing proposition. In other words, the referent of the dislocated constituent, for example, EDUCATION, or BEATLES in (8), functions as a framing device (cf.

\footnotetext{
${ }^{16}$ Although the referent of the dislocate in example (6) is coreferential with the possessive determiner nja (his), it cannot be said that the referent of the dislocated constituent is coreferential with the referent of the constituent, ibu-nja (his mother). The semantic relationship between the demonstrative dislocate (Anak itu / that child) and the clause internal NP (ibu-nja / his mother) is, therefore, not considered prototypical (i.e. total identity), but rather metonymic.
} 
Fillmore 1982) that constrains the interpretation of the following proposition to a certain semantic domain (cf. Villalba 2000: 109).

In the LD constructions discussed thus far, the dislocated status of the leftmost constituent is grammatically determined by the lack of an alternative slot (e.g. semantic or syntactic dependency relation) within the predicate-argument structure of the clause. This is either due to the presence of a co-referential element, as in H-Type and C-Type constructions, or other semantically or pragmatically linked elements, as in the Chinese-style constructions.

Additionally, the dislocated status of the leftmost constituent may be confirmed on the basis of its position relative to other sentence elements, such as discourse particles and interjections, focus elements, interrogative particles, negative particles, and conjunctions. Discourse particles and interjections, for example, typically occur in a sentence initial position outside the boundary of the clause. It follows then, that any constituent preceding a discourse particle would, ipso facto, also occur outside of the clause. For instance, Greenberg (1984) observed that a topicalized constituent in English cannot occur in front of an extra-clausal interjection, unlike their dislocated counterparts. For Greenberg, this is a clear indication that topicalized constituents are tightly integrated into the structure of the clause, and that dislocated constituents, conversely, are positioned outside of that structure. The ungrammaticality of (9b) in comparison to (9a), illustrates Greenberg's observation.

English (Greenberg, 1984:285) ${ }^{17}$
a. $\quad\left[J_{o h n}\right]_{i}$, man, Mary really loves him $_{i}{ }^{18}$
(LD)
b. *John, man, Mary really loves
(Topicalization)

Moreover, Chafe illustrates the same constraint in the Amerindian language of Caddo, as seen in (10), in which the interjection is marked in bold:

Cado (Chafe, 1976:52)

[Sa?u?úšs $]_{i}$, bah?na sinátti? tučát?i.hahwah

"Ms. Owl, they say, she spilled it"

Conjunctions and interrogatives have also been shown to mark clause boundaries across languages, such that constituents positioned before these elements are understood to be dislocated outside the clause. In the Malayo-Polynesian language of Kambera, for example, a conjunction marks the clause boundary, and formally differentiates LD constructions from the structurally similar fronting constructions. In other words, a conjunction must precede the frontmost constituent in a fronting construction, while, in LD constructions, a conjunction always follows the front-most constituent. Hence, the conjunction, along with an intonation break,

\footnotetext{
17 The interjections are marked in bold.

18 The fact that interjections can also precede constitutes whose dislocated status is confirmed by a intra-clausal coreferential resumptive further confirms the extra-clausal status of the interjection (e.g. "Man, [John] , Mary really loves himi").
} 
serve to mark the preceding constituent as dislocated from the core clause. The examples in (11) illustrate this difference (Klamer 1998: 88):

(11) Kambera (Klamer 1998: 88)

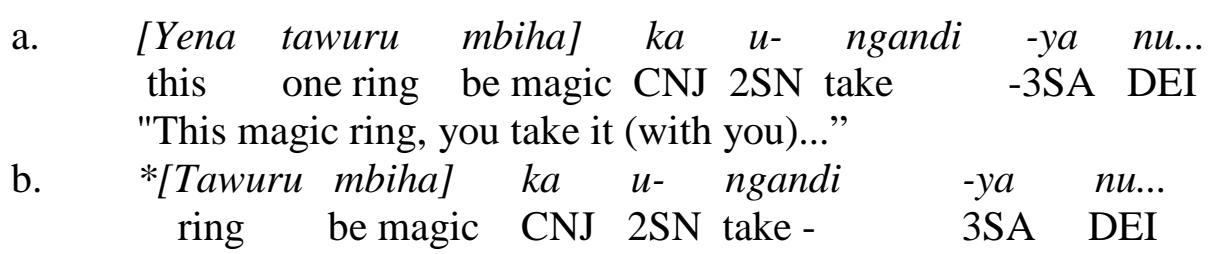

(Fronting)

Likewise, in the Arabic examples in (12), an interrogative serves to mark the initial clause boundary.

(12) Arabic (Lambrecht ibid: citing Moutaouakil 1989)
a. $\quad[\text { Zayd }]_{i}, \quad$ ?a najaha masru'uhu $u_{i}$ ? Zayd-NOM Q succeeded plan-NOM-3S.GEN
"Zayd, did his plan come off?"
b. *?a [Zayd] i najaha masru 'uhui?

Thus, in (12a), the proper noun Zayd is considered dislocated due to its position preceding the interrogative, whereas in (12b), the position of the proper noun after the interrogative results in ungrammaticality.

Indeed, additional grammatical evidence could be discussed, such as negative particles, and focus elements (cf. Lambrecht 2001 for more details); however, the above examples suffice to illustrate the present point: In addition to the lack of an available position within the clause, the dislocated status of the leftmost constituent(s) may be further substantiated by its position relative to other clause boundary markers. ${ }^{19}$

\section{Cognitive Motivation and Discourse-Pragmatic Function}

\subsection{Cognitive Motivation}

In light of the syntactic and semantic profile sketched thus far, the discussion now turns to the explanations that have been proposed for the construction's function in discourse. In addressing this aspect of LD, it is necessary to distinguish between: 1) the cognitive-pragmatic constraints motivating both the use of LD in particular contexts, and 2) the communicative goals and pragmatic effects achieved by the use of the construction in discourse.

Beginning with the constraints motivating the use of $\mathrm{LD}$, it is commonly observed that there exists a natural proclivity, across languages, for speakers and writers to first introduce a new

\footnotetext{
${ }^{19}$ It should be kept in mind that the notion of an extra-clausal position is itself a complex concept only detectable by indirect tests. As a result it should be viewed as a scalar concept, as noted above.
} 
referent before predicating some property about it (Lambrecht, 1994: 177-178). This presentational task is typically accomplished by one of two cross-linguistically attested constructions.

First, the bi-clausal "presentational construction" functions to introduce so-called "brand new" referents into the discourse. The referent is first introduced by either a deictic or existential clause, such as the English there-construction, which is then followed by a second clause that contains a predication about the referent introduced in the first clause. Moreover, this second clause may be syntactically independent or dependent to the first clause, as the two presentational constructions in (13) illustrate:
a. There once was a bear. He lived in a cave in the woods
b. There once was a bear who lived in a cave in the woods

In other contexts, however, speakers find themselves needing to introduce referents that are not purely brand-new, but merely inactive. In other words, the referent is assumed to be identifiable to the addressee, but only minimally accessible to her, having been in one way or another evoked in the prior discourse or in the extra-linguistic context (Lambrecht 2001: 1073). Under these circumstances, the LD constructions, rather than the presentational construction, is the preferred grammatical strategy for the (re)introduction, or (re)activation of discourse referents. Indeed, several empirical studies have led many to conclude that the primary motivation for the use of LD concerns the assumed low degree of cognitive accessibility entertained by the referent at the time the construction is used. ${ }^{20}$ While both the presentational and LD constructions prototypically function to introduce referents into the discourse, the primary difference between them lies in the assumed cognitive status of the referents in the mind of the addressee. If the referent is assumed to be brand-new, then a presentational construction is preferred, while if the referent is identifiable and minimally accessible, the LD construction is used.

As an aside, two parameters are generally employed to estimate the assumed cognitive status of discourse referents in any given context. These are: 1) the particular form of a referring expression, and 2) the degree to which the referent has been evoked in either the preceding discourse, or the extra-linguistic context.

Beginning with the form of referring expression, research has shown that the type of expression used by the speaker in a given context is constrained by the assumed degree of accessibility the referent entertains in the mind of the addressee (cf. Prince 1981, Gundel et al. 1993, Ariel 1990, 2001). Thus, referring expressions can be understood as accessibility markers, which, to some extent, encode specific degrees of accessibility (Ariel 2001: 31).

A variety of competing models have been proposed in an effort to sufficiently account for this constraint. Most notable among these include Ariel's "Accessibility Scale” (Figure 1) and the "Givenness Hierarchy” formulated by Gundel, Hedberg and Zarcharski (Figure 2).

${ }^{20}$ Cf. Kuzar and Netz (2007, 2010) and Kuzar, Netz, and Eviatar (2011). 
Full name+modifier $>$ full name $>$ long definite description $>$ short definite description $^{21}>$ last name $>$ first name $>$ distal demonstrative+modifier $>$ proximate demonstrative + modifier $>$ distal demonstrative $+\mathrm{NP}>$ proximate demonstrative $+\mathrm{NP}>$ distal demonstrative(-NP) $>$ proximate demonstrative $(-\mathrm{NP})>$ stressed pronoun+gesture $>$ stressed pronoun $>$ unstressed pronoun $>$ criticized pronoun $>$ verbal person inflections $>$ zero

Figure 1: The Accessibility Scale (Ariel 1990: 73).

The Accessibility Scale moves from high to low such that Full name + modifier represents the lowest marker of accessibility and zero represents the highest. According to Ariel these formfunction pairings are motivated by three overlapping criteria: Informativity (i.e. the amount of lexical information provided by the expression), Rigidity (i.e. the ability to pick out a unique referent based on the form), and Attenuation (i.e. the phonological size of the expression). In other words, the more informative, rigid and unattenuated an expression, the lower the degree of accessibility and vice versa (Ariel 2001.: 32).

Similarly, Gundel et al.'s Givenness Hierarchy predicts the assumed degree of accessibility of a referent based on the form of the referring expression used. However, in contrast to Ariel's Accessibility Scale, the Givenness Hierarchy is formulated as a linear entailment scheme in which each status entails every other status to its right:

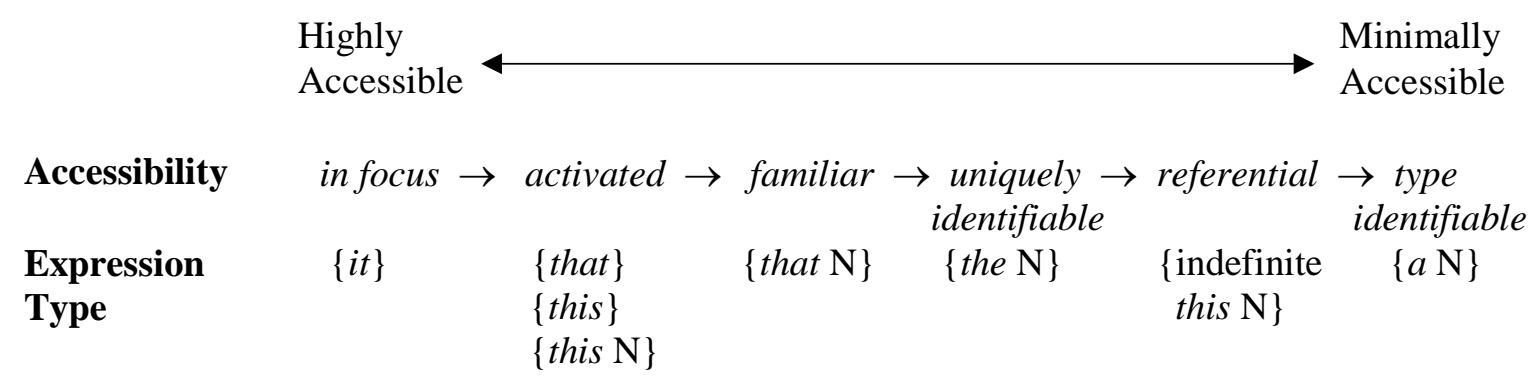

Type Identifiable: The addressee is able to access a representation of the type of object described by the expression.

Referential: $\quad$ The addressee is able to access a representation of the type of object described by the expression.

Uniquely The addressee can identify the speaker's intended referent on the basis of Identifiable: the nominal alone.

Familiar: $\quad$ The addressee can uniquely identify the intended referent on the basis of an existing representation in memory.

Activated: $\quad$ The referent is represented in current short-term memory.

In Focus: $\quad$ The referent is at the current center of attention.

Figure 2: The Givenness Hierarchy

\footnotetext{
${ }^{21}$ Ariel is careful to highlight the fact that, contra other theories (e.g. Chafe 1994), definite descriptions count as "quite low accessibility markers" here (Ariel 2001: 31n6).
} 
Although seemingly minor, this distinction is far from trivial, as it accounts for exceptions where, for instance, a low accessibility marker is used to encode a referent that is highly accessible, a phenomenon often termed "referential over-encoding". Such over-encoding exploits the expectations predicted by the givenness hierarchy in order to trigger specific pragmatic implicatures. For instance, a definite NP, canonically used to encode uniquely identifiable referents, may be used to encode a referent that is highly active (e.g. Gundel et al.'s "in focus"). Due to the potential mismatch between grammatical form and accessibility status, the capacity for over-encoding is problematic for determining the accessibility of a referent solely on the basis of its referential form. In order to account for this variable, the source of a referent's accessibility, either through its prior evocation in the discourse, or its presence in the extra-linguistic context, is used as an additional measure for determining the referent's cognitive status at the time it is uttered.

For example, some referents are explicitly introduced in a discourse, after which they undergo a process of cognitive decay moving from the center of consciousness to the periphery, either because of lack of mention or replacement. Depending on either the textual distance or length of time from its last mention, these so-called "textually accessible" referents may be assumed to entertain a low degree of accessibility.

Alternatively, the source of a referent's accessibility may be based on an implicit relation with another explicitly evoked entity in the context. In other words, the accessibility of the referent may derive from an addressee's ability to infer it from other explicitly evoked entities in the context. This may happen as a result of a semantic frame relation or a so-called "partially ordered set relation". For example, in the sentence "I went for a run yesterday, and [the trail], $i t_{i}$ went on forever!", the identifiability and accessibility of the definite dislocated NP the trail is due to the inference evoked by the "running" frame, triggered in the first clause. In other words, the trail is inferable from the assumed knowledge that running often happens on trails.

Lastly, some referents have neither been textually or inferentially evoked in the prior discourse context but are nevertheless accessible due to their presence in the extra-linguistic context. ${ }^{22}$ That is to say that a referent is assumed to be accessible simply because of its presence in the text-external world shared by the speech participants. For example, while on a walk with my wife I might say "[those leaves] $]_{\mathrm{i}}$, they are so big." with reference to leaves on a tree which I assume my wife is not presently aware of but which, nevertheless, I assume are accessible to her. $^{23}$

\footnotetext{
22 See also Khan (2016).

${ }^{23}$ It should be mentioned that, besides tapping directly into the brain, determining the accessibility of a referent often involves a complex array of factors. For instance, Ariel (2001) contends that accessibility is determined by text-external and text-internal factors; but she is careful to clarify that discoursal (i.e. text-internal) factors always trump those from the physical context (i.e. text-external). One factor determining accessibility is referred to by Ariel as Salience. Salience concerns the discourse role and prominence of a particular entity in a stretch of discourse. "Discourse topics and other entities mentioned or reliably predicted to be relevant to the discourse at hand can receive high or low degrees of accessibility according to their discourse role" (Ariel 2001: 31). Yet, as Ariel argues, it is the discoursal rather than physical salience of the entities involved that determines the degree of accessibility assigned to particular referents (ibid.). "Whereas the physical accessibility of the speaker in the real world does not change in the course of the conversation, her discourse role and prominence in it may" (ibid.: 32).

In addition to saliency, other factors contributing to the relative degree of accessibility include the relationship between the antecedent and the anaphor in terms of unity or cohesion (Ariel, 1990). This relationship may be tight, resulting in a higher degree of accessibility, or loose, resulting in a lower one. Competition between potential
} 
Returning to the discussion of motivation, both the bi-clausal presentational construction and the LD constructions involve the syntactic separation of a constituent from its canonical position within the clause expressing the main predication (cf. Lambrecht 1994: 184). According to Lambrecht, this separation eases the cognitive processing cost associated with the (re)introduction of new referents. In other words, if there were no separation, "the mental effort necessary to interpret the proposition which expresses the new information about the topic would be performed simultaneously with another processing task, the task of remembering, inferring, or otherwise determining the referent of the topic expression" (Lambrecht 1994: 166). Lambrecht refers to this constraint as "The Principle of the Separation of Reference and Role" (=PSRR) which he sums up with the maxim "do not introduce a referent and talk about it in the same clause" (ibid.: 185). In light of this constraint, it becomes evident that the uniquely partitioned form of the LD construction is cognitively motivated. In other words, an iconic relation exists between the grammatical form of the construction and an underlying cognitive constraint.

\subsection{Discourse-Pragmatic Functions}

\subsubsection{The Interactional Approach}

In light of these motivating constraints, we now turn our attention to the overarching communicative goals and pragmatic effects that are achieved by the use of LD in discourse. In doing so, we find that the research is divided into two related but distinct approaches. The first approach has its origins in sociology and is principally concerned with the social and interactional nature of communication, such as the conversational setting, participant relationships and the s0-called turn taking system within a discursive exchange.

Under this approach, the LD construction functions as a "floor-seeking" device, employed by the speaker in order to seek, occupy and hold onto the direction of talk and thus control the social situation at hand (Duranti and Ochs, 1979: 403). In their study of LD in Italian spoken conversation, for instance, Duranti and Ochs found that LD constructions were specifically used to achieve this interactional objective. In addition, they observed that the construction was used not only to gain access to the speaking floor, but to block or reduce the access of others participating in the social interaction (ibid.: 405). In addressing the question of why the LD construction in particular is used for this interactional purpose, Duranti and Ochs surmise that the construction is effectively used to shift attention from some immediate point of reference

antecedents is another factor. "The more potential antecedents there are, the lower the degree of accessibility each is entertained with" (ibid.). Finally, following Givón (1983, 1992), Ariel avers that the distance between anaphor and antecedent is critical in assessing the degree of accessibility. Contra Givón, however, she argues that word or clauses are not the only measures of distance. Paragraphs and episode boundaries also create a type of distance between anaphor and antecedent, despite the fact that they may be in close linear proximity to one another. This is because people have more trouble accessing information at episode boundaries (ibid.). By contrast, units (clauses) that are more cohesively linked entail more dependency in their interpretation since "material from one clause is more readily available for the interpretation of another" (ibid.). The more cohesively linked clauses results in a higher degree of accessibility. Similarly, looser connections require more independent cognitive processing since there is less availability (accessibility) of material in one clause for the interpretation of the other (ibid.). Ariel contends that "such differences account for the different anaphoric patterns observed for subordinations (higher degree of accessibility—repeated proper names are clearly dispreferred) verses coordination (a lower degree of accessibility)" (ibid.). 
to a different point of reference that is relevant to some aspect of the prior conversational exchange (ibid.: 407).

Moreover, following Duranti and Ochs, Geluykens (1992) has explained the function of LD in English conversation in light of the turn-taking system. In other words, changes of speaker operate according to a rule-based system in which speakers manage floor allocation on a turnby-turn basis (for further discussion see, Levinson 1983: 296ff). In light of this turn management system, Geluykens argues that LD is prototypically used for the "introduction of irrecoverable, topical referents, by way of an interactional, three stage collaborative process" illustrated by the exchange in (14) adapted from Geluykens (1992: 35):

\author{
Speaker 1-Turn A: "Now [the last paragraph] $]$ \\ Speaker 2-Turn B: "yes" \\ Speaker 1-Turn C: "I seem to remember it $t_{i}$ being different from what's printed"
}

Speaker 1 (re)introduces a referent in the first turn, which speaker 2 is expected to acknowledge in the second turn, after which Speaker 1 completes the proposition in the third turn. Despite this rather idealized example, Geluykens acknowledges that most of the constructions he analyzed, lacked a second intervening turn. The first turn was rather followed by an intervening pause between the dislocated constituent and the core clause. According to Geluykens, these silent pauses function as place holders for the second turn. Although no verbal acknowledgment is provided, the pause is not interpreted as a lack of acknowledgment, but as a silent indication that the identification of the referent has been satisfactorily established on the part of the hearer (ibid.:42). ${ }^{24}$ Thus, from a diachronic perspective, the pause represents the first stage of grammaticalization, as this three-stage process of (re)introducing referents into the discourse gradually coalesces into a mono-propositional LD structure. ${ }^{25}$

\title{
3.2.2 The Informational Approach: Prototypical Functions
}

Notwithstanding the insights gained from an interactional perspective, most researchers have adopted an alternative, and in many ways, more generalized approach when examining the function of LD in discourse. This approach is linguistic in origin and understands the function of communication to be the exchange of information as a means of influencing an addressee's mental representation to match that of the speaker (cf. Verhagen 2005). Such an approach is inherently cognitive in nature and is directly related to the cognitive-pragmatic motivations for the use of LD discussed above.

In particular, it is argued that LD is, at its most basic level, a discursive strategy used to facilitate the (re)activation of referents that are assumed to entertain a low degree of accessibility in the mind of the addressee. As discussed above, this (re)activation function is motivated foremost by the processing constraint stipulated by the PSRR. The LD construction mitigates the high processing cost that would have been incurred by having to activate an inactive referent while

\footnotetext{
24 By contrast, Ford et al. (2003) and Tizón-Couto (2012) argue that the acknowledgement turn is not necessary, but optional. For these authors, the inherent quality of the process is the pause after the initial referent is uttered. If an acknowledgement does occur, it is simply a by-product of Grice's (1989) cooperative principle (Tizón-Couto 2012: 312).

25 Cf. Westbury (2014), Andrason et al. (2016).
} 
simultaneously having to interpret the semantic and pragmatic roles of the referent in the proposition.

Aside from its (re)activation function, it is commonly held that LD solely functions as a topic marking strategy across languages. Consequently, it is not uncommon for linguists to refer to the dislocated constituent simply as the "Topic Phrase" or some equivalent thereof. Yet, this is, strictly speaking, not accurate for two reasons, one of which we will address presently, while circling back to the other further below.

The dislocated constituent cannot function as the topic expression because it is syntactically detached from the clause which encodes the pragmatically structured proposition. Since the topic relation only exists relative to a proposition, it follows that the topic expression must occupy a position within the syntactic dependency relations of the clause. ${ }^{26}$ Thus, while the dislocated constituent serves to (re)activate the referent, the topic relation is satisfied by the coreferential resumptive or otherwise semantically linked element within the clause. ${ }^{27}$

In light of this distinction, we can say that, in addition its basic level function of (re)activating inactive referents, the LD construction is prototypically a "Topic Announcing” construction. In other words, LD is used to (re)activate a referent in order to ratify it as a suitable topic for the associated proposition. This follows from the long observed fact that active referents constitute the most acceptable topics across languages (cf. Givón 1983, Lambrecht 1994, inter alia). It also explains why resumptives prototypically take the form of a pronoun. As both the Accessibility Scale and the Givenness Hierarchy predict, pronouns are the preferred expression type for active referents. The following short paragraph in (15), adapted from Lambrecht (1994: ;177) illustrates this “Topic Announcing” function:

(15) (a) "Once there was a king who was very wise. He was rich, and was married to a beautiful queen. (b) They had two sons. The first was tall and brooding, he spent his days in the forest hunting snails, and his mother was afraid of him. The second was short and vivacious, a bit crazy but always game. (c) [Now the king] , he $_{\mathrm{i}}$ lived in Switzerland...”

Having been initially activated by the bi-clausal presentational construction in sentence (a), the active status of the referent KING begins to decay as the referent ceases to be talked about or even mentioned in the subsequent propositions represented in (b). Therefore, upon needing to say something else about the KING, the writer employs an LD construction in (c) in order to reactivate the referent, and ratify it as a suitable topic for the associated proposition. It is also worth noting, that the (re)activated referent, in addition to functioning as a sentence-level topic, may also function as a topic of a stretch of discourse, a so-called "Discourse Topic". In other words, the newly activated entity functions as a "global organizing referent" about which the

\footnotetext{
${ }^{26}$ Note that this becomes less clear in cases where resumption is absent, and where LD becomes closer to Fronting

${ }^{27}$ Lambrecht also recognizes the inherent contradiction in referring to the dislocated constituent as "Topic Phrase". He writes: "Since a detached lexical topic constituent does not occupy an argument position in a clause, it is strictly speaking not with the lexical topic NP but with the anaphoric pronominal topic expression that the pragmatic aboutness relation [i.e. topic, JRW] between the referent and the proposition is expressed. It is therefore slightly inconsistent to call such a detached lexical constituent a 'topic NP'. Rather it is a 'topic-announcing' NP" (Lambrecht, 1994.: 188).
} 
reader's attention is oriented for a stretch of discourse (cf. van Dijk 1977, Brown and Yule 1983, Barnes 1983, Chafe 1994, Callow 1998, Floor 2004, inter alia).

Although the topic announcing function seems to be typologically prototypical, further crosslinguistic evidence reveals that LD is also used to announce the focus of a proposition (cf. Yamaizumi 2011). This is illustrated by the Japanese LD construction in (16):

Japanese (Yamaizumi 2011: 83)

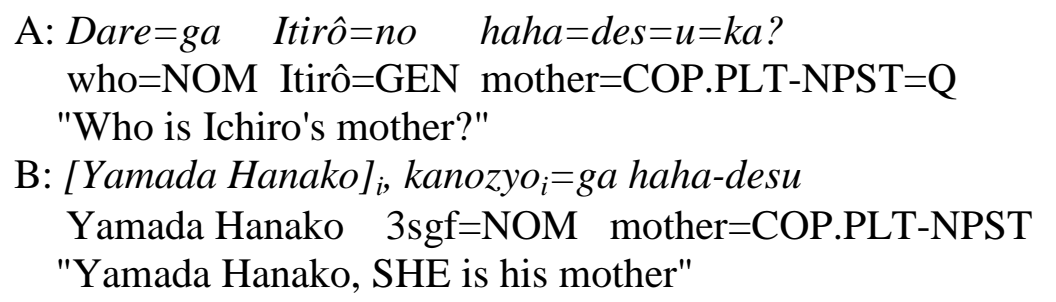

The dislocation of Yamada Hanako in B's reply functions to (re)activate the referent of the proper name. In the proposition that follows, however, the coreferential resumptive pronoun "she" is not the topic, but rather supplies the missing argument in the presupposed open proposition: “X is Ichiro’s mother” (cf. Yamaizumi 2011 for further examples and discussion).

Moreover, this constitutes the second reason for why the dislocated constituent should not be universally thought of as a Topic Phrase. In addition to the fact that the constituent is situated outside the syntactic dependency relations of the clause, the referent may, as the example in (13) illustrates, be the focus of the proposition, not the topic. Thus, the processing constraint stipulated by the PSRR can be generalized to motivate both the (re)activation of referents that satisfy a topic or a focal relation to the proposition. In other words, the task of determining the identity of a referent is separated from the task of interpreting the referent's pragmatic role (i.e. Topic or Focus) within the proposition.

As an extension to its basic level function of (re)activation, the LD construction may also be used to activate a particular attribute of an already highly accessible referent (cf. Ono and Thompson 1994, Tizón-Couto 2012 for further discussion). This function is represented in the LD construction in (17):

(17) A: Was it you or my brother who forgot the pizza

$\mathrm{B}$ : [That forgetful brother of yours] $]_{\mathrm{i}}, \mathrm{HE}_{\mathrm{i}}$ forgot the pizza

Speaker B's answer to A's question consists of a Focus Announcing LD construction. However, the referent of the dislocated constituent YOUR BROTHER is already highly active as a result of Speaker A's question. Moreover, the complex phrase used to encode this referent (e.g. that forgetful brother of yours) is more informative than needed to identify it. In other words, speaker B could have answered with the less informative but sufficient phrase your brother. The motivation for the use of LD in such cases derives not from the low accessibility of the referent, but rather from the activation of some new attribute or profile against which the referent is recast. Such referring expressions are typically structurally complex and highly informative, thus triggering the use of LD in accordance with the PSRR. 


\subsubsection{The Informational Approach: Non-Prototypical Functions}

Although LD is prototypically used for the (re)activation of referents entertaining a low degree of accessibility, the construction may also be used in marked contexts, in which the dislocated referent is already highly active. Such uses constitute what Givón has called "the over-use of discourse machinery" (1979: 153-154). Since there is no need to (re)activate the referent, the use of LD results in an interference or disruption of cognitive processing, rather than a facilitation of it. In particular, expectations associated with the prototypical use of LD are exploited, thereby producing an ostensive stimulus that signals an additional pragmatic inference. In terms of classical Gricean pragmatics, the speaker flouts the Maxim of Quantity in order to produce specific pragmatic implicatures, depending on the context. The addressee, in turn, recognizes that the speaker has violated the maxim, and thus infers the intended implicature.

For example, the disruption in cognitive processing caused by the unexpected dislocation of highly accessible/active referents often signals a development shift in the discourse (cf. Lambrecht 1994: 184, Manetta 2007). This is illustrated by the sample text in (18), adapted from Lambrecht:

(18) a. CONTEXT: Once there was a king. He was very wise, powerful and was married to a beautiful queen. He lived in a magnificent castle by the lake. He had forty-nine servants, and he owned an important collection of rare books.

b. DEVELOPMENT SHIFT: Now [The king] , he $_{i}$ was very ambitious. He had been planning for years to conquer the world and finally he was ready. ${ }^{28}$

Section (a) begins with the introduction of the referent KING which then functions as the topic of the following propositions. As a result of its highly active status and topical role, the reader naturally expects the referent to continue as a pronominal topic expression (e.g. $\mathrm{He}$ ) in the subsequent discourse. ${ }^{29}$ Yet, the sentence beginning section (b) exploits this expectation by both dislocating and over-encoding the highly active referent. In addition to the discourse particle Now, the use, or overuse of LD in this context signals to the reader that a development shift in the discourse has occurred.

Alternatively, LD is sometimes used to mark a shift in attention between two or more highly accessible, or active topics (Lambrecht 1994: 183). This typically has the added effect of explicitly enhancing a contrastive or comparative relation between propositions that would have otherwise been left implicit. For example, consider the two sentences in (19), adapted from Lambrecht:

\section{Lotta guys don't ask me. [Me $]_{i} I_{i}$ ask}

Although the speaker in (16) is highly active, he or she is not the expected topic of the second sentence. Rather, since the referent LOTTA GUYS is the topic of the first sentence, the addressee would naturally expect the same referent to function as the topic in the second

\footnotetext{
${ }^{28}$ Manetta (2007) observes similar uses of LD in spoken English discourse which she refers to as "Unexpected LDs".

${ }^{29}$ Cf. Givón's (1983) discussion of topic-continuity in discourse.
} 
sentence. Thus, rather than (re)activating an inactive referent, the use of LD in this context is motivated by the desire to mark an unexpected shift in attention to another active referent-in this case, the speaker. Moreover, not unlike the example in (15), this unexpected use of LD causes a disruption in the processing of the discourse. This disruption functions to enhance the inherent contrastive relation between the juxtaposed propositions. In particular, the proposition in the second sentence, "I ask" serves to contradict and eliminate the assumption implicit in the first sentence, namely that the speaker “doesn't ask”.

Finally, from a diachronic perspective, these non-prototypical functions represent the outer fuzzy edges of the LD category, where the construction begins to functionally (and structurally) overlap with other construction types (e.g. fronting) as it moves further along the grammaticalization cline. This is evident, for instance, in the functional patterns associated with the H-Type and C-Type classifications described above. Indeed, there is evidence to suggest that, beyond their structural differences, H-Type and C-Type LDs tend to be associated with distinct discourse functions as well (cf. Lopez, forthcoming). In particular, H-Type LDs are generally associated with referents that entertain a low degree of accessibility and accomplish a broad range of discourse functions, while C-Type constructions, tend to be more constrained to highly accessible referents, and are generally used to mark a contrastive relation between two or more propositions-two functions prototypically associate with fronting constructions. This complies with the structural evidence presented above (cf. section 2.1) which suggests that C-Type constructions represent a more advanced stage of the grammaticalization cline, where LD gradually moves closer to the prototypical fronting construction (and then on to unmarked word order).

\section{Conclusion}

As a typologically universal category, the LD construction exhibits a diverse array of syntactico-semantic and discourse-pragmatic features across languages. Accordingly, particular tokens may be more or less prototypical depending on the degree to which they reflect the typologically prototypical schema (cf. section 2.1). Moreover, among the diversity of syntactic types across languages, a variety of patterns have been observed that have led researchers to postulate a few heuristic structural categories-the two most common being Hanging Topic LD (H-Type) and Clitic LD (C-Type). H-Type and C-Type constructions differ structurally both in terms of their connectivity effects and their syntactic distribution. Where $\mathrm{H}$-Type constructions typically exhibit less connectivity between the dislocate and the associated clause and more constraints with respect to syntactic distribution, C-Type constructions typically exhibit more connectivity and fewer distribution constraints.

As a final syntactic consideration, so-called non-resumptive LD constructions were considered. These constructions represent a highly non-prototypical type of LD where an initial constituent that is detached from the matrix clause to some degree, however, no overt co-referential resumptive occurs within the clause. Despite the lack of a co-referential resumptive, Nonresumptive dislocates may be semantically related to another constituent within the clause, or to the clause as a whole.

The syntactic differences between these construction types showcase their varying prototypically effects, with H-Type construction being considered more prototypical on average, while C-Type, and Non-resumptive LDs are less prototypical. Moreover, these 
prototypicality effects also correlate with the position of each construction type on a diachronic grammaticalization cline. From this perspective, H-Type construction are lower on the cline (i.e. less grammaticalized), while C-Type and Non-resumptive constructions are higher on the cline and therefore closer to the fuzzy LD category boundary. This explains why, for instance, C-Type and Non-resumptive constructions may share attributes with other constructional categories (e.g. fronting).

The typological-functional explanations for LD have centered on: 1) the motivating constraints for the use of LD in particular contexts, and 2) the communicative goals and pragmatic effects achieved by the use of the construction in discourse. Together, these two perspectives provide a coherent functional profile of the LD category. With respect to the former, the use of LD is prototypically motivated by the need to talk about (topic) or assert (focus) a referent which entertains a low degree of cognitive accessibility in the mind of the addressee. In terms of the latter, LD is prototypically used as a communicative strategy for efficiently (re)activating a minimally accessible referent and talking about it (or asserting it) within the same construction. Accordingly, the partitioned structure of the LD construction separates, thereby mitigating, two cognitively costly processing tasks, viz. the task of identifying a referent, and the task of interpreting pragmatic role of the referent (i.e. Topic or Focus) within the proposition.

LD is also often used in contexts where the referent is already highly active, and thus, there is no need for reactivation. Rather than mitigating cognitive processing costs, in these contexts LD rather impedes cognitive processing, often for the intended purpose of signaling various non-prototpyical pragmatic implicatures. Moreover, this functional profile of LD-described in terms of a continuum of prototypically-often corresponds typologically with the structural distinction between $\mathrm{H}$-type and C-type constructions. In particular, $\mathrm{H}$-type tends to accomplish prototypical functions, while C-type corresponds to less-prototypical functions, thus lending further evidence that C-type constructions generally represent a more advanced stage on the grammaticalization cline.

\section{References}

Anagnostopoulou, E. 1994. Clitic Dependencies in Modern Greek. PhD dissertation, University of Salzburg.

Anagnostopoulou, E. 1997. Clitic left dislocation and contrastive left dislocation. In E. Anagnostopoulou, H. van Riemdijk and F. Zwarts (Eds.) Materials on Left Dislocation. Amsterdam/Philadelphia: John Benjamins. pp. 151-192.

Anagnostopoulou, E., H. van Riemdijk, and F. Zwarts (Eds.) 1997. Materials on Left Dislocation. Amsterdam/Philadelphia: John Benjamins.

Andrason, A. 2016. To resume or not to resume: Some remarks on 'resumption' in left dislocation constructions in Polish, and its relevance for Biblical Hebrew. Stellenbosch Papers in Lingusitics Plus 50. 185-199.

Andrason, A., J. Westbury, C.H.J. van der Merwe. 2016. Left dislocation: An exploration in linguistic typology. Stellenbosch Papers in Linguistics Plus 50. 1-20. 
Aoun, J. and E. Benmamoun 1998. Minimality, Reconstruction and PF Movement. Linguistic Inquiry 29. 569-598.

Aoun, J. and L. Choueiri 2000. Epithets. Natural Language \& Linguistic Theory 18(1). 1-39.

Ariel, M. 1990. Accessing Noun Phrase Antecedents. London: Routledge.

Ariel, M. 2001. Accessibility theory: an overview. In T. Sanders, J. Schilperoord, \& W. Spooren (Eds.) Text Representation: Linguistic and Psycholinguistic Aspects. Amsterdam/Philadelphia: John Benjamins Publishing Company. pp. 29-88.

Arnaudova, O. 2004. Saliency and contrast in colloquial Bulgarian: clitic left dislocation and contrastive topicalization. In B. Shaer, W. Frey and C. Maienborn (Eds.) Proceedings of the Dislocated Elements Workshop. Berlin: ZAS. pp. 15-39.

Alexiadou, A. 2006. Left dislocation (including CLLD). In M. Everaert and H.C. van Riemsdijk (Eds.) Blackwells Companion to Syntax, Vol. 2. Malden, MA: Blackwell Publishing, pp. 669699.

Baker, M. 1996. The Polysynthesis Parameter. Oxford University Press.

Baker, M. 2003. Agreement, dislocation, and partial configurationality. In A. Carnie, H. Harley, and M. Willie (Eds.) Formal Approaches to Function in Grammar: In Honor of Eloise Jelinek. Amsterdam/New York: John Benjamins. pp. 107-132.

Barnes B.K. 1985. The Pragmatics of Left Detachment in Spoken Standard French. Amsterdam: John Benjamins.

Barcelona-Sanchez, A. 1988. El Tópico Desgajado en Inglés: Motivación Pragmática. Atlantis, 10. 9-20.

Bresnan, Joan and Samuel A. Mchombo 1987. Topic, Pronoun, and Agreement in Chicheŵ. Language 63. 741-782.

Boeckx, C. and Kleanthes G. 2005. Left dislocation in Germanic. In W. Abraham (Ed.) Focus on Germanic Typology. Berlin: Akademie-Verlag. pp. 131-144.

Chomsky, N. 1977. Essays on Form and Interpretation. Amsterdam: North-Holland.

Cinque, G. 1983/1997. 'Topic' Constructions in some European languages and 'connectedness'. In E. Anagnostopoulou, H.V. Riemsdijk and F. Zwarts (Eds.) Materials on Left Dislocation. Amsterdam/Philadelphia: John Benjamins. pp. 93-118.

Croft, W. 1990. Typology and Universals. Cambridge: Cambridge University Press.

De Cat, C. 2007a. French Dislocations. Oxford University Press. 
De Cat, C. 2007b. French Dislocation without Movement. Natural Language and Linguistic Theory 25. 485-534.

Delais-Roussaire, E., Doetjes, J., and Sleeman, P. 2004. Dislocation. In F. Corblin and H. de Swart (Eds.) Handbook of French Semantics. Palo Alto: CSLI Publications. pp. 505-530.

Dobrovie-Sorin, C. 1994. The Syntax of Romanian. Berlin: Mouton de Gruyter.

Feldhausen, I. 2012. Prosodic Aspects of Clitic Left Dislocation in Spanish. Unpublished manuscript, University of Frankfurt and Université Paris 3 Sorbonne Nouvelle.

Fillmore, C. 1982. Frame Semantics. In The Linguistic Society of Korea (Eds.) Linguistics in the morning calm. Seoul: Hanshin. pp. 111-37

Frascarelli, M. 2000. The Syntax-Phonology Interface in Focus and Topic Constructions in Italian. Dordrecht: Kluwer.

Frey, W. 2005. Pragmatic Properties of Certain English and German Left Peripheral Constructions. Linguistics 43. 89-129.

Geluykens, R. 1992. From Discourse Process to Grammatical Construction: On LeftDislocation in English. Amsterdam: John Benjamins.

Geluykens, R. 1993. Syntactic, semantic and interactional prototypes: the case of left Dislocation. In R.A. Geiger and B. Rudzka-Ostyn (Eds.) Conceptualizations and Mental Processing in Language, (Vol. 3 of Cognitive Linguistic Research). New York/Berlin: Walter de Gruyter. pp. 709-730.

Givón T. 1979. On Understanding Grammar. New York: Academic Press.

Givón T. 1983. Topic Continuity in Discourse: A Quantitative Cross-Language Study. TSL. Vol. 3. Amsterdam: John Benjamins.

Givón T. 1992. The Grammar of Referential Coherence as Mental Processing Instructions. Linguistics 30. 5-55.

Greenberg, G.R. 1984. Left Dislocation, Topicalization, and Interjections. Natural Language \& Linguistic Theory 2(3). 283-287.

Grice, H.P. 1989. Studies in the Way of Words. Cambridge, MA: Harvard University Press.

Gross, W. 1987. Die Pendenskonstruktion im biblischen Hebräisch. St. Otillien: EOS.

Grohmann, K. 2003. Prolific Domains. Philadelphia/Amsterdam: John Benjamins.

Gundel, J. 1975. Left Dislocation and the Role of Topic-Comment Structure in Linguistic Theory. Working Papers in Linguistics 18. 72-31. 
Gundel, J., Hedberg, N. \& Zacharski, R. 1993. Cognitive Status and the Form of Referring Expressions in Discourse. Language 69(2). 274-307.

Haegeman, L. 1991. Introduction to Government and Binding Theory. Oxford: Blackwell.

Hirschbühler, P. 1975. On the Source of Lefthand NPs in French. Linguistic Inquiry 6. 155165.

Holmstedt, R. 2015. Critical at the Margins: Edge Constituents in Biblical Hebrew. KASATU 17. 109-156.

Kallulli, D. 1999. The Comparative Syntax of Albanian: The Contribution of Syntactic Types to Propositional Interpretation. PhD dissertation, University of Durham.

Khan, G. 1988. Studies in Semitic Syntax. Oxford: Oxford University Press.

Khan, G. 2016. Left Dislocation in North-Eastern Neo-Aramaic Dialects. Stellenbosch Papers in Linguistics Plus 50. 91-110.

Klamer, M. 1998. A grammar of Kambera. Berlin/New York: Mouton de Gruyter.

Korchin, P. 2015 Suspense and Authority Amid Biblical Hebrew Front Dislocation. Journal of Hebrew Scriptures 15(1). 1-46.

Lasnik, H. and Saito, M., 1992. Move $\alpha$ : Conditions on its Applications and Output. Cambridge, Mass: MIT Press.

Lambrecht, K. 1981. Topic, Antitopic, and Verb Agreement in on-standard French. Amsterdam: John Benjamins.

Lambrecht, K. 1994. Information Structure and Sentence Form: Topic, Focus and the Mental Representation of Discourse Referents. New York: Cambridge University Press.

Lambrecht, K. 2001. Dislocation. In M. Haspelmath, E. Konig, W. Oesterreicher, and W. Raible (Eds.) Typology and Language Universals. Berlin: Walter de Gruyter. pp. 1050-1078.

Li, C. and Thompson, S.A. 1976. Subject and topic: a new typology of language. In C. Li and S.A. Thompson (Eds.) Subject and Topic. New York: Academic Press. pp. 457-489.

Lopez, L. Forthcoming. Dislocations. In C. Féry and S. Ishihara (Eds). Oxford Handbook of Information Structure. Oxford: Oxford University Press.

Lyons, C. 1999. Definiteness. Cambridge: Cambridge University Press.

Manetta, E. 2007. Unexpected Left Dislocation: An English Corpus Study. Pragmatics 39. 1029-1034. 
Moezzipour, F. 2013. Towards Rethinking Left-Detached Position and Pre-Core Slot in RRG: Evidence from Clitic Left-Dislocation Constructions in Persian.

https://www.researchgate.net/publication/259044914_Towards_rethinking_the_LeftDetached_Position_in_RRG_Evidence_from_external_possession_in_Persian

Moutaouakil, A. 1989. Pragmatic Functions in a Functional Grammar of Arabic. Providence: Foris Publications.

Morvacsik, E. 2010. Explaining language universals. In Song (Ed.) Oxford Handbook of Linguistic Typology. Oxford University Press: Oxford. pp. 69-89.

Naudé. J.A. 1990. A Syntactic Analysis of Dislocations in Biblical Hebrew. Journal of Northwest Semitic Languages XVI. 115-130.

Olarrea, A. 2012. Word Order and Information Structure. In J.I. Hualde, A. Olarrea, and E. O’Rourke (Eds.) The Handbook of Hispanic Linguistics. Malden, MA: Blackwell Publishing. pp. 603-628.

Ott, D. Forthcoming. An Ellipsis Approach to Contrastive Left-Dislocation. Linguistic Inquiry.

Radford, A. 1988. Transformational Grammar. Cambridge: Cambridge UP.

Rivero, M.L. 1980. On Left Dislocation and Topicalization in Spanish. Linguistic Inquiry 11. 363-393.

Rizzi, L. 1997. The Fine Structure of the Left Periphery. In L. Haegeman (Ed.) Elements of Grammar. Dordrecht: Kluwer. pp. 281-337.

Ross, J. 1967. Constraints on Variables in Syntax. PhD dissertation, MIT.

Rodman, R. 1974/1997. On left dislocation. In E.V. Riemskijk, H. Zwarts, and F. Anagnostopoulou (Eds.) Materials on Left Dislocation. Amsterdam: John Benjamins, pp. 3154. [Originally in Papers in Linguistics 7. 473-466.]

Samek-Lodovici, V. 2006. When Right Dislocation Meets the Left-Periphery. A Unified Analysis of Italian Non-final Focus. Lingua 116. 836-873.

Samek-Lodovici, V. 2005. Prosody-syntax interaction in the expression of focus. Natural Language and Linguistic Theory 23. 687-755.

Sturgeon, A. 2006. The Syntax and Pragmatics of Contrastive Topic in Czech. PhD dissertation, University of California Santa Cruz.

Tizón-Couto, D. 2012. Left Dislocation in English: A Functional-Discoursal Approach. Bern: Peter Lang.

Van der Spuy, A. 1993. Dislocated Noun Phrases in Nguni. Lingua 90(4). 335-355. 
Van Riemsdijk, H. 1997. Left dislocation. In E. Anagnostopoulou, H. Riemsdijk, and F. Zwarts (Eds.) Materials on Left Dislocation. Amsterdam/Philadelphia: John Benjamins. pp. 1-12.

Van Riemsdijk, H. \& Zwarts, F. 1974/1997. Left dislocation in Dutch and the status of copying rules. In E. Anagnostopoulou, H. van Riemsdijk, and F. Zwarts (Eds.), Materials on Left Dislocation. Amsterdam: John Benjamins. pp. 13-30.

Vat, J. 1981/1997. Left dislocation, connectedness and reconstruction. In E. Anagnstopoulou, H.V. Riemsdijk and F. Zwarts (Eds.) Materials on Left Dislocation. Amsterdam/Philadelphia: John Benjamins. pp. 67-92.

Verhagen, A. (2005). Constructions of Intersubjectivity: Discourse, Syntax, and Cognition. Oxford: Oxford University Press.

Villalba, X. 2000. The Syntax of Sentence Periphery, PhD dissertation. Universitat Autònoma de Barcelona.

Villalba, X. 2009. The Syntax and Semantics of Dislocations in Catalan. Köln: Lambert Academic Publishing.

Westbury, J. 2014. Left Dislocation in Biblical Hebrew: A Cognitive Linguistic Approach. PhD dissertation, University of Stellenbosch.

Zaenen, A. 1997. Contrastive dislocation in Dutch and Icelandic. In E. Anagnostopoulou, H.V. Riemsdijk and F. Zwarts (Eds.) Materials on Left Dislocation. Amsterdam/Philadelphia: John Benjamins. pp. 119-150.

Yamaizumi, M. 2011. Left Dislocation in Japanese and Information Structure Theory. NINJAL Research Papers 1. 77-92.

Zólyomi, G. 2005. Left dislocated possessors in Sumerian. In É.K. Kiss (Ed.) Universal Grammar in the Reconstruction of Ancient Languages (Studies in Generative Grammar, 83). New York: Mouton de Gruyter 2005. pp. 161-188. 